\title{
Characterization of Pathos VICT Graph of a Tree
}

\author{
M. H. Muddebihal, Jayashree B. Shetty
}

\author{
Department of Mathematics Gulbarga University Kalaburgi-585106 Karnataka India \\ Department of Mathematics Government, First Grade, College Humnabad-585330 Karnataka India
}

\begin{abstract}
In this paper, the concept of pathos Vict graph of a tree is introduced. Its study is concentrated only on trees. A characterization of those graphs whose pathos Vict graph of a tree are planar, outerplanar, maximal outerplanar, minimally nonouterplanar, maximal minimally nonouterplanar and crossing number one were obtained. Also a necessary and sufficient conditions for $P V_{n}(T)$ to be eulerian is established.
\end{abstract}

Keywords: $\operatorname{PVn}(\mathrm{T})$

\section{Introduction}

The concept of pathos of a graph $\mathrm{G}$ was introduced by Harary[2] as a collection of minimum number of edge disjoint open paths whose union is $\mathrm{G}$. The path number of a graph $\mathrm{G}$ is the number of paths in pathos.

Stanton [6] and Harary [4] have calculated the path number for certain classes of graphs like trees and complete graphs. The path number of a tree $\mathrm{T}$ is equal to $\mathrm{K}$, where $2 \mathrm{~K}$ is the number of odd degree vertices of $\mathrm{T}$. Also the endvertices of each path of any pathos of a tree are odd vertices is given by Gudagudi [1]. All undefined terminologies will conform with that in Harary [3]. All graphs considered here are finite, undirected and without loops or multiple edges. The pathos vict graph of a tree $\mathrm{T}$, denoted as $\mathrm{PV}_{\mathrm{n}}(\mathrm{G})$ is defined as the graph whose vertex set is the union of the set of vertices, set of cutvertices and set of paths of pathos of $\mathrm{T}$, in which two vertices are adjacent if and only if corresponding vertices of $\mathrm{T}$ are adjacent and the vertices lies on the path $\mathrm{P}_{\mathrm{i}}$ of pathos and the vertices are adjacent to the cutvertices.

Since the system of pathos for a tree is not unique, the corresponding pathos vict graph is also not unique. In Fig1 , a tree $\mathrm{T}$ and its different pathos Vict graphs $\mathrm{PV}_{\mathrm{n}}(\mathrm{T})$ are shown.

The edge degree of an edge uv of a tree $\mathrm{T}$ is the sum of the degrees of $u$ and $v$. The pathos length is the number of edges which lie on a particular path $\mathrm{P}_{\mathrm{i}}$ of pathos in T. A pendant pathos is a path $\mathrm{P}_{\mathrm{i}}$ of pathos having unit length which corresponds to a pendant edge in $\mathrm{T}$. A pathos vertex is a vertex in $\mathrm{PV}_{\mathrm{n}}(\mathrm{T})$ corresponding to the path $\mathrm{P}_{\mathrm{i}}$ of pathos in $\mathrm{T}$.

The following results are required to prove our further results.

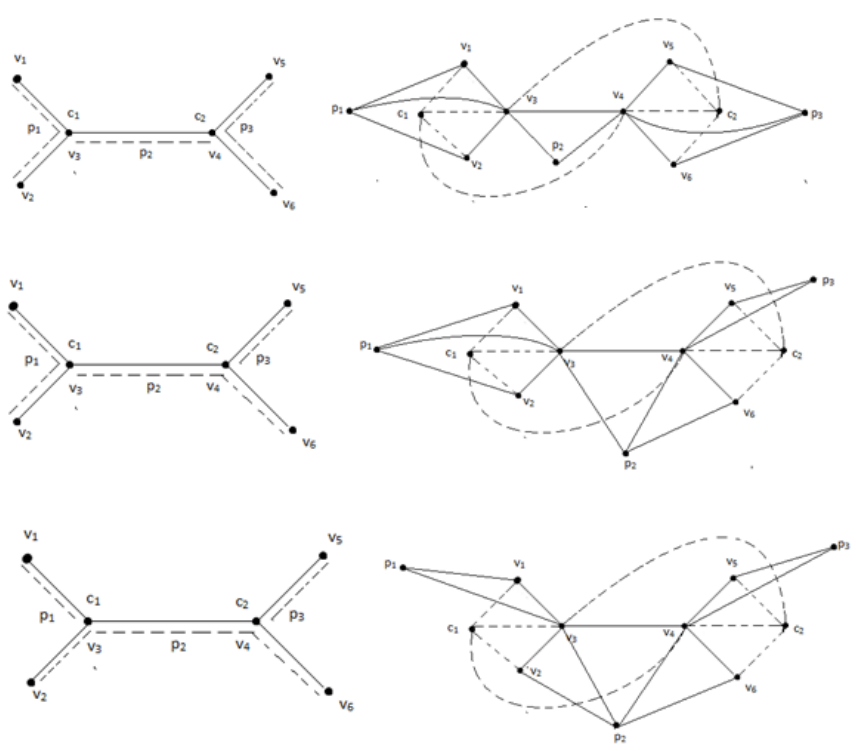

Figure 1

The following results are required to prove our further results.

Theorem A[5]: If $\mathrm{G}$ is a nontrivial connected (p, $\mathrm{q}$ ) graph, $\mathrm{Ci}$ be the number of cutvertices in $\mathrm{G}$ and li be the number of edges incident with the cutvertices in $\mathrm{G}$. Then vict graph $V_{n}(G)$ has $p+i=0 n C_{i}$ vertices and $\left[i=0 n\left(l_{i}+C_{i}\right)\right]+q$ edges.

Theorem B[5]: Let $\mathrm{G}$ be (p, q) graph. Then vict graph $\mathrm{V}_{\mathrm{n}}(\mathrm{G})$ is outerplanar if and only if $\mathrm{G}$ is nonseparable outerplanar and $\mathrm{G}$ is either a path or a cycle.

Theorem C[3]: A graph $\mathrm{G}$ is outerplanar if and only if it has no subgraph homeomorphic to $\mathrm{K}_{4}$ or $\mathrm{K}_{2,3}$.

Theorem D[3]: Every maximal outerplanar graph $\mathrm{G}$ with $\mathrm{p}$ vertices has $(2 \mathrm{p}-3)$ edges.

Theorem E[3]: If $G$ is any planar $(p, q)$ graph with $p \geq 3$, then $\mathrm{q} \leq 3 \mathrm{p}-6$. Furthermore, if $\mathrm{G}$ has no triangles then $\mathrm{q} \leq 2 \mathrm{p}-$ 4.

\section{Pathos Vict Graphs}

We start with few preliminary results. 


\section{International Journal of Science and Research (IJSR) \\ ISSN (Online): 2319-7064}

Index Copernicus Value (2013): 6.14 | Impact Factor (2015): 6.391

Remark 1: No vertex of $P V_{n}(T)$ is a cutvertex.

Remark 2: The edge degree of an edge uv in a tree is odd if the degree of one vertex is even and other odd.

Remark 3: The edge degree of every edge in a tree is even if and only if every vertex is of odd degree.

Remark 4: For any tree $T, V_{n}(T)$ is a subgraph of $\mathrm{PV}_{n}(T)$.

Remark 5: The degree of the pathos vertex in $\mathrm{PV}_{\mathrm{n}}(\mathrm{T})$ is equals to the pathos length of the corresponding path $\mathrm{P}_{\mathrm{i}}+1$ of paths in $\mathrm{T}$.

Remark 6: Every pendantpathos in a tree $\mathrm{T}$ corresponds to a pendant edge in $\mathrm{PV}_{\mathrm{n}}(\mathrm{T})$ which adds one vertex to $\mathrm{PV}_{\mathrm{n}}(\mathrm{T})$.

Remark 7: If $\mathrm{T}=\mathrm{K}_{1, \mathrm{n}}$ where $\mathrm{n}$ is even. Then degree of each pathos vertex $\mathrm{p}_{\mathrm{i}}$ is 3 .

Remark 8: If $\mathrm{T}=\mathrm{K}_{1, \mathrm{n}}$ where $\mathrm{n}$ is odd. Then degree of each pathos vertex $p_{i}$ is 3 except one pathos vertex, which is of degree two.

In the following theorem we obtained the number of vertices and edges in a pathos vict graph.

Theorem 1: If a graph $\mathrm{G}$ is a (p, q) graph where $\mathrm{Ci}$ be the number of cutvertices in $\mathrm{G}$, li be the number of edges incident with the cutvertices in $G, k$ be the number of paths in $\mathrm{G}$ and $\mathrm{Pi}$ be the path length of a pathos, the pathos vict graph $P V_{n}(T)$ has $p+k+i=1 n\left(C_{i}\right)$ vertices and $\left[i=1 n\left(C_{i}+l_{i}\right)+q\right]+\left[i=1 n\left(P_{i}+1\right)\right]$ edges.

Proof: By the definition, the number of vertices in $\mathrm{PVn}(\mathrm{T})$ is $p+k+i=1 n(C i)$. By Theorem $A$, the number of edges in $\mathrm{Vn}(\mathrm{G})$ is $[\mathrm{i}=\ln (\mathrm{Ci}+\mathrm{li})+\mathrm{q}]$.

The number of edges in $\mathrm{PVn}(\mathrm{T})$ is the sum of edges in $\mathrm{Vn}(\mathrm{G})$ and the number of vertices which lie on the paths Pi of pathos of $G$, by the Remark 5, which is $i=1 n(P+1)$. Hence the number of edges in $\operatorname{PVn}(T)$ is $\left[i=1 n\left(C_{i}+l_{i}\right)+q\right]+$ $\left[i=1 n\left(P_{i}+1\right)\right]$.

\section{Planar pathos vict graphs}

A criterion for pathos vict graph to be planar is presented in the next theorem.

Theorem 2: The pathos vict graph $\mathrm{PV}_{\mathrm{n}}(\mathrm{T})$ of a tree $\mathrm{T}$ is planar if and only if $\mathrm{T}$ does not contain two adjacent cutverices, which are adjacent to at least two paths, in which path of pathos does not contain these adjacent cutvertices and their neighbours.

Proof: Suppose $\mathrm{PV}_{\mathrm{n}}(\mathrm{T})$ is planar. Then $\mathrm{V}_{\mathrm{n}}(\mathrm{T})$ is planar. Now assume there exist two adjacent cutvertices $u$ and $w$ which are adjacent with at least two paths $P_{n}, P_{m}$ at $u$ and $\mathrm{P}_{\mathrm{s}}, \mathrm{P}_{\mathrm{t}}$ at $\mathrm{w}$ with path length $\mathrm{n}, \mathrm{m}, \mathrm{s}, \mathrm{t} \geq 1$. Suppose there exist a path of pathos $P_{1}$ which contains $x \in N(u), y \in$ $N(w), u, w$ and paths either $P_{n}, P_{t}$ or $P_{s}, P_{m}$. Now assume $P_{1}$ contains $\mathrm{P}_{\mathrm{m}}, \mathrm{P}_{\mathrm{s}}, \mathrm{u}, \mathrm{w}, \mathrm{x}$ and $\mathrm{y}$. Then the remaining paths of pathos $\mathrm{P}_{\mathrm{A}}$ contains $\mathrm{P}_{\mathrm{n}}$ and path of pathos $\mathrm{P}_{\mathrm{B}}$ contains $\mathrm{P}_{t}$.

Since $\mathrm{u}, \mathrm{w}, \mathrm{x}, \mathrm{y}, \mathrm{p}_{\mathrm{l}}, \mathrm{p}_{\mathrm{A}}$ and $\mathrm{p}_{\mathbf{B}}$ are the vertices of $\mathrm{PV}_{\mathrm{n}}(\mathrm{T})$ and $\mathrm{u}^{\prime}, \mathrm{w}^{\prime}$ be the vertices of $\mathrm{PV}_{\mathrm{n}}(\mathrm{T})$ corresponding to $\mathrm{u}$ and $w$. Then in $\mathrm{PV}_{\mathrm{n}}(\mathrm{T})$, the edges joining uu', ux, uw, ww', wy, $\mathrm{p}_{\mathrm{l}} \mathrm{u}, \mathrm{p}_{\mathrm{l}} \mathrm{w}, \mathrm{p}_{\mathrm{l}} \mathrm{x}, \mathrm{p}_{\mathrm{l}} \mathrm{y}$ any two edges intersecting in any plane embedding of $\mathrm{PV}_{\mathrm{n}}(\mathrm{T})$, a contradiction.

Conversely, suppose $\mathrm{T}$ Satisfies the conditions of the theorem, on plane embedding of $\mathrm{PV}_{n}(T)$, the vertex $\mathrm{p}_{\mathrm{l}}$ is not adjacent to either $\mathrm{x}$ or $\mathrm{y}$. Suppose it is not adjacent to $\mathrm{x}$. Then the both the cutvertices $\mathrm{u}^{\prime}, \mathrm{w}^{\prime}$ are adjacent to $\mathrm{x}$ and $\mathrm{y}$ without any intersection in any plane embedding.

Hence $\mathrm{PV}_{\mathrm{n}}(\mathrm{T})$ is planar.

We now present a characterization of tree whose pathos vict graphs are outerplanar.

Theorem 3. The pathos vict graph $\mathrm{PV}_{\mathrm{n}}(\mathrm{T})$ of a tree $\mathrm{T}$ is outerplanar if and only if $\mathrm{G} \cong K_{2}$.

Proof. Suppose $\mathrm{PV}_{\mathrm{n}}(\mathrm{T})$ is outerplanar. Assume $\mathrm{T}$ has a vertex $\mathrm{v}$ of degree 2. The edges incident to $\mathrm{v}$ and the cutvertex $\mathrm{v}$ forms an induced subgraph homeomorphic to $\mathrm{K}_{4}$. Hence $\mathrm{PV}_{\mathrm{n}}(\mathrm{T})$ is nonouterplanar, a contradiction.

Conversely, suppose $T$ is a path $P_{t}$ of length $t \leq 1$. By Theorem $B, V_{n}(T)$ is nonseperable outerplanar.

For $\mathrm{t}=0$, the result is obvious.

For $t=1$, the vertices joining to $V_{n}(T)$ from the corresponding pathos vertex gives $\mathrm{PV}_{\mathrm{n}}(\mathrm{T})$ which is a triangle. By Theorem $\mathrm{C}, \mathrm{PV}_{\mathrm{n}}(\mathrm{T})$ is outerplanar.

We now present a characterization of tree whose pathos vict graphs are maximal outerplanar.

Theorem 4: The pathos vict graph $\mathrm{PV}_{\mathrm{n}}(\mathrm{T})$ of a tree $\mathrm{T}$ is maximal outerplanar if and only if $\mathrm{T}$ is a $\mathrm{K}_{2}$.

Proof: Suppose $\mathrm{PV}_{\mathrm{n}}(\mathrm{T})$ is maximal outerplanar. Then $\mathrm{PV}_{\mathrm{n}}(\mathrm{T})$ is connected. Hence $\mathrm{T}$ is connected. If $\mathrm{PV}_{\mathrm{n}}(\mathrm{T})$ is $\mathrm{K}_{3}$, then obviously $\mathrm{T}$ is $\mathrm{K}_{2}$.

Let $T$ be any connected tree with $p \leq 2$ vertices, $q$ edges, $C_{i}$ cutvertices, $l_{i}$ be the number of edges incident with the cutvertices in $T, k$ be the number of paths in $G$ and $P_{i}$ be the path length of a pathos.

Then $\quad \mathrm{PV}_{\mathrm{n}}(\mathrm{T})$ has $\left[\mathrm{p}+\mathrm{k}+\mathrm{i}=1 \mathrm{n}\left(\mathrm{C}_{\mathrm{i}}\right)\right]$ vertices and $\left[\mathrm{i}=1 \mathrm{n}\left(\mathrm{l}_{\mathrm{i}}+\mathrm{C}_{\mathrm{i}}\right)+\mathrm{q}\right]+\left[\mathrm{i}=1 \mathrm{n}\left(\mathrm{P}_{\mathrm{i}}+1\right)\right.$ edges. Since $\mathrm{PV}_{\mathrm{n}}(\mathrm{T})$ is maximal outerplanar, by Theorem $\mathrm{D}$, it has $2\left[\mathrm{p}+\mathrm{k}+\mathrm{i}=1 \mathrm{n}\left(\mathrm{C}_{\mathrm{i}}\right)\right]-3$ edges. Hence,

$\left[i=1 n\left(l_{i}+C_{i}\right)+q\right]+\left[i=1 n\left(P_{i}+1\right)\right]=2\left[p+k+i=1 n\left(C_{i}\right)\right]-3$.

Thus for $\mathrm{T}=\mathrm{K}_{2}$ we have $\mathrm{l}_{\mathrm{i}}=0, \mathrm{C}_{\mathrm{i}}=0, \mathrm{p}=2, \mathrm{k}=1, \mathrm{P}_{\mathrm{i}}=1$ and $\mathrm{q}=1$.

$[i=1 n(0+0)+1]+i=1 n(1+1)=2[2+1+i=1 n 0]-3$ 


\section{International Journal of Science and Research (IJSR)}

ISSN (Online): 2319-7064

Index Copernicus Value (2013): 6.14 | Impact Factor (2015): 6.391

$1+1+1=2[2+1]-3$

$3=2[3]-3$

$3=6-3$

$3=3$

By Theorem D, it follows that $\mathrm{G}$ is a $\mathrm{K}_{2}$

Necessity is thus proved.

For sufficiency, suppose $T$ is a path, $P_{n}(n \leq 2)$. Then we consider two cases.

Case1: Assume $\mathrm{T}$ is $\mathrm{K}_{1}$. Then $\mathrm{PV}_{\mathrm{n}}(\mathrm{T})=\mathrm{K}_{1}$. Hence it is maximal outerplanar.

Case2: Assume $\mathrm{T}$ is $\mathrm{K}_{2}$. Then $\mathrm{PV}_{\mathrm{n}}(\mathrm{T})=\mathrm{K}_{3}$, Which is maximal outerplanar.

For any plane graph $G$ the inner vertex number $i(G)$ of $G$ is the minimum number of vertices not belonging the boundary of the exterior region in any embedding of $\mathrm{G}$ in the plane. We call the inner vertex number $\mathrm{i}(\mathrm{G})$ as Kulli number.

A graph $\mathrm{G}$ is said to be minimally nonouterplanar if Kulli number is one or $\mathrm{i}(\mathrm{G})=1$.

In the next theorem we establish the result in which $\mathrm{PV}_{\mathrm{n}}(\mathrm{T})$ has a Kulli number one.

Theorem 5: For any tree $\mathrm{T}, \mathrm{PV}_{\mathrm{n}}(\mathrm{T})$ has a Kulli number one if and only if $\Delta(\mathrm{T}) \leq 2$ for every vertex $\mathrm{v}$ of $\mathrm{T}$ and $\mathrm{T}$ has a unique vertex of degree two.

Proof: Suppose $\mathrm{PV}_{\mathrm{n}}(\mathrm{T})$ has a Kulli number. Assume $\Delta$ $(\mathrm{T})>2$. Let $\mathrm{v}$ be a vertex with $\operatorname{deg}(\mathrm{v})=3$, let $\mathrm{v}_{1}, \mathrm{v}_{2}, \mathrm{v}_{3}$ are adjacent to $\mathrm{v}$. In $\mathrm{V}_{\mathrm{n}}(\mathrm{T})$ has a subgraph homeomorphic to $\mathrm{K}_{2,3}$. Since it has two pathos vertices. Then any one vertex lies in the interior region of embedded $\mathrm{PV}_{\mathrm{n}}(\mathrm{T})$. Hence Kulli number of $\mathrm{PV}_{\mathrm{n}}(\mathrm{T})$ is more than one, a contradiction. Hence $\Delta(\mathrm{T})=2$.

Assume that there exist at least two vertices of degree 2 in $T$. Then $V_{n}(T)$ has at least two blocks as $P_{3}+K_{1}$. Since $T$ has exactly one pathos, let $\mathrm{v}$ be a pathos vertex which is adjacent to all the vertices of $\mathrm{P}_{3}+\mathrm{K}_{1} \mathrm{P}_{3}+\mathrm{K}_{1}$. On embedding $\mathrm{PV}_{\mathrm{n}}(\mathrm{T})$ in any plane it has at least two Kulli number, a contradiction.Hence $\mathrm{T}$ has exactly one vertex of degree two.

Conversely, suppose every vertex of $\mathrm{T}$ has degree $\leq 2$ and has a unique vertex of degree 2 . Then $\mathrm{V}_{\mathrm{n}}(\mathrm{T})$ has exactly one block as $\mathrm{K}_{4}-\mathrm{X}$. A pathos vertex $\mathrm{v}$ is adjacent to every vertex of tree $\mathrm{T}$.

Which gives $\mathrm{W}_{5}$ as a subgraph. Hence $\mathrm{PV}_{\mathrm{n}}(\mathrm{T})$ has a Kulli number one.

In the next theorem we prove that $\mathrm{PV}_{\mathrm{n}}(\mathrm{T})$ is maximal minimally nonouterplanar.

Theorem6: For any tree $\mathrm{T}, \mathrm{PV}_{\mathrm{n}}(\mathrm{T})$ has maximal Kulli number one if and only if $\Delta(\mathrm{T}) \leq 2$ has unique vertex of degree 2.
Proof: Suppose $\mathrm{PV}_{\mathrm{n}}(\mathrm{T})$ of tree $\mathrm{T}$ has maximal Kulli number one. We consider the following cases.

Case1: If $\Delta(\mathrm{T})<2$. Then by Theorem $4, \mathrm{PV}_{\mathrm{n}}(\mathrm{T})$ is maximal outerplanar, a contradiction.

Case2: If $\Delta(\mathrm{T})>3$. Then by Theorem $5, \mathrm{PV}_{\mathrm{n}}(\mathrm{T})$ has greater than Kulli number one, a contradiction.

Case3: If $\mathrm{T}$ has at least two vertices of degree 2. Then $\mathrm{PV}_{\mathrm{n}}(\mathrm{T})$ has greater than Kulli number one, a contradiction.

Case4: If $\mathrm{T}$ has a unique vertex $\mathrm{v}$ of degree 2. By Theorem $5, \mathrm{PV}_{\mathrm{n}}(\mathrm{T})$ has Kulli number one. Now we Show that $\mathrm{PV}_{\mathrm{n}}(\mathrm{T})$ has maximal Kulli number one. Since $\mathrm{T}=\mathrm{K}_{1,2}$, then $\mathrm{V}_{\mathrm{n}}(\mathrm{T})=\mathrm{K}_{4}$ - $\mathrm{x}$ and $\mathrm{PV} \mathrm{V}_{\mathrm{n}}\left(\mathrm{K}_{1,2}\right)=\mathrm{W}_{5}$.

Which has maximal Kulli number one.

The next theorem characterizes $\mathrm{PV}_{\mathrm{n}}(\mathrm{T})$ in terms of crossing number one.

Theorem 7: The pathos vict graph $\mathrm{PV}_{\mathrm{n}}(\mathrm{T})$ of a tree $\mathrm{T}$ has a crossing number one if and only if for any tree $\mathrm{T}$ with $\Delta$ (T) $\geq 3$ has exactly two adjacent vertices $v_{1}$ and $v_{2}$ with $\Delta$ (T) and remaining vertices are of degree either one or two. Also the path of pathos contains $\mathrm{v}_{1}, \mathrm{v}_{2}, \mathrm{~N}\left(\mathrm{v}_{1}\right)$ and $\mathrm{N}\left(\mathrm{v}_{2}\right)$.

Proof: Suppose pathos vict graph of a tree $\mathrm{T}$ has crossing number one. Then $\mathrm{V}_{\mathrm{n}}(\mathrm{T})$ is planar. Now we assume $\Delta(T) \geq 2$. Then we consider the following cases.

Case1: Assume $\Delta(\mathrm{T})=2$. Then $\mathrm{T}=\mathrm{Pn}$. By Theorem1 and Theorem E, $[\mathrm{i}=\ln (\mathrm{Ci}+\mathrm{Ii})+\mathrm{q}]+[\mathrm{i}=\ln (\mathrm{Pi}+1)] \leq 3 n-6$. Hence $\operatorname{Cr}[\operatorname{PVn}(\mathrm{T})]=0$, a contradiction.

Case2: Assume $\Delta(\mathrm{T}) \geq 3$ and $\mathrm{T}$ has exactly two adjacent vertices $v_{1}$ and $v_{2}$ with $\Delta(T)$ and remaining vertices are of degree either one or two. Also the path of pathos contain $\mathrm{v}_{1}, \mathrm{v}_{2}, \mathrm{~N}\left(\mathrm{v}_{1}\right)$ and $\mathrm{N}\left(\mathrm{v}_{2}\right)$. Then we consider following subcases of case 2 .

Subcase 2.1: Suppose $T$ has three cutvertices $v_{1}, v_{2}$ and $v_{3}$ of degree $\Delta(T)$. Further assume that $v_{1}$ is adjacent to $v_{2}$ and $v_{2}$ is adjacent to $v_{3}$ and path of pathos contains these three vertices. Then in $\mathrm{PV}_{\mathrm{n}}(T),\left\{\mathrm{v}_{1}, \mathrm{v}_{2}, \mathrm{~N}\left(\mathrm{v}_{1}\right), \mathrm{v}_{3} \mathrm{v}_{1}^{\mathrm{I}}, \mathrm{v}_{2}^{\mathrm{I}}\right\}$ forms a subgraph homeomorphic to $\mathrm{K}_{3}, 3$ where $\mathrm{v}_{1}^{\mathrm{I}}, \mathrm{v}_{2}^{\mathrm{I}}$ are corresponding vertices of $\mathrm{v}_{1}, \mathrm{v}_{2}$. Also $\left\{\mathrm{v}_{3}, \mathrm{v}_{2}, \mathrm{v}_{1}, \mathrm{v}_{2}^{\mathrm{I}}, \mathrm{v}_{3}^{\mathrm{I}}\right.$, $\mathrm{N}\left(\mathrm{v}_{3}\right)$ \} forms another subgraph homeomorphic to $\mathrm{K}_{3,3}$ where $\mathrm{v}_{2}{ }^{\mathrm{I}}, \mathrm{v}_{3}{ }^{\mathrm{I}}$ are cut vertices and $\mathrm{v}_{2}{ }^{\mathrm{I}}, \mathrm{v}_{3}{ }^{\mathrm{I}} \in \mathrm{V}\left[\mathrm{PV}_{\mathrm{n}}(\mathrm{T})\right]$. Hence $C_{r}\left[P V_{n}(T)\right]>1$, a contradiction.

Subcase 2.2: Suppose path of pathos does not contain either $\mathrm{N}\left(\mathrm{v}_{1}\right)$ or $\mathrm{N}\left(\mathrm{v}_{2}\right)$. Now assume path of pathos contain $\mathrm{N}\left(\mathrm{v}_{1}\right)$. Then there exist $\mathrm{v}_{1}{ }^{\mathrm{I}}$ and $\mathrm{v}_{2}{ }^{\mathrm{I}} \in \mathrm{PV}_{\mathrm{n}}(\mathrm{T})$ where $\mathrm{v}_{1}{ }_{1}^{\mathrm{I}}, \mathrm{v}_{2}{ }^{\mathrm{I}}$ corresponds to $\mathrm{v}_{1}, \mathrm{v}_{2} \in \mathrm{T}$. In $\mathrm{PV}_{\mathrm{n}}(\mathrm{T}), \mathrm{v}_{1}{ }^{\mathrm{I}}$ is adjacent to $\mathrm{v}_{1}$ and $\mathrm{N}\left(\mathrm{v}_{1}\right)$. And $\mathrm{v}_{2}{ }^{\mathrm{I}}$ is adjacent to $\mathrm{v}_{2}$ and $\mathrm{N}\left(\mathrm{v}_{2}\right)$ and pathos vertex $\mathrm{p}_{1}$ which is adjacent to $\mathrm{v}_{1}, \mathrm{v}_{2}$ and $\mathrm{N}\left(\mathrm{v}_{1}\right)$. Thus in planar embedding of $\mathrm{PV}_{\mathrm{n}}(\mathrm{T})$ in any plane, $\mathrm{PV}_{\mathrm{n}}(\mathrm{T})$ is planar. Thus $C_{r}\left[P_{n}(T)\right]=0$, a contradiction. On the other hand if path of pathos contains $\mathrm{N}\left(\mathrm{v}_{2}\right)$, we have $\mathrm{C}_{\mathrm{r}}\left[\mathrm{PV}_{\mathrm{n}}(\mathrm{T})\right]=0$ again, a contradiction. 


\section{International Journal of Science and Research (IJSR) \\ ISSN (Online): 2319-7064}

Index Copernicus Value (2013): 6.14 | Impact Factor (2015): 6.391

Conversely, suppose $\mathrm{T}$ holds the condition of the Theorem. Let $v_{1}$ and $v_{2}$ are two adjacent cut vertices of degree $\Delta(T) \geq 2$, such that $\mathrm{v}_{1}{ }^{\mathrm{I}}$ and $\mathrm{v}_{2}{ }^{\mathrm{I}} \in \mathrm{PV}_{\mathrm{n}}(\mathrm{T})$, corresponding to $\mathrm{v}_{1}, \mathrm{v}_{2} \in \mathrm{T}$. Then there exist a pathos vertex $\mathrm{p}_{1}$ which lies on $\mathrm{v}_{1}, \mathrm{v}_{2}, \mathrm{~N}\left(\mathrm{v}_{1}\right)$ and $\mathrm{N}\left(\mathrm{v}_{2}\right)$.

In $\mathrm{PV}_{\mathrm{n}}(\mathrm{T}), \mathrm{v}_{1}{ }^{\mathrm{I}}$ is adjacent to $\mathrm{v}_{1}$ and $\mathrm{N}\left(\mathrm{v}_{1}\right)$, also $\mathrm{v}_{2}{ }^{\mathrm{I}}$ is adjacent to $\mathrm{v}_{2}$ and $\mathrm{N}\left(\mathrm{v}_{2}\right), \mathrm{p}_{1}$ is adjacent to $\mathrm{v}_{1}, \mathrm{v}_{2}, \mathrm{~N}\left(\mathrm{v}_{1}\right)$ and $\mathrm{N}\left(\mathrm{v}_{2}\right)$. This adjacency produces an induced subgraph homeomorphic to $\mathrm{K}_{3,3}$

Hence $\mathrm{C}_{\mathrm{r}}\left[\mathrm{PV}_{\mathrm{n}}(\mathrm{T})\right]=1$.

The noneulerian property of $\mathrm{PV}_{\mathrm{n}}(\mathrm{T})$ is giving by the following theorem.

Theorem 8: For any nontrivial tree $T$ with $p \geq 3$ vertices $\mathrm{PV}_{\mathrm{n}}(\mathrm{T})$ is noneulerian.

Proof: Suppose $\mathrm{T}$ is a tree with $\mathrm{p}<3$ vertices. Then $\mathrm{T}$ is either $\mathrm{K}_{1}$ or $\mathrm{K}_{2}$. Assume if $\mathrm{T}=\mathrm{K}_{1}, \mathrm{PV}_{\mathrm{n}}(\mathrm{T})=\mathrm{K}_{1}$ and if $\mathrm{T}=\mathrm{K}_{2}$, $\mathrm{PV}_{\mathrm{n}}(\mathrm{T})=\mathrm{K}_{3}$. Then $\mathrm{PV}_{\mathrm{n}}(\mathrm{T})$ is eulerian

Suppose $T$ is a tree with $p \geq 3$ verices. Let $A=\left\{v_{1}, v_{2}\right.$, -.-.-. $\left.\mathrm{v}_{\mathrm{n}}\right\}$ be the set of vertices such that $\operatorname{deg}\left(\mathrm{v}_{\mathrm{i}}\right)=$ odd, $\forall \mathrm{V}_{\mathrm{i}} \in A$ and $B=\left\{v_{1}, v_{2}, \ldots .-, v_{m}\right\}$ be the set of vertices in which each $\mathrm{v}_{\mathrm{j}} \in \mathrm{B}, \operatorname{deg}\left(\mathrm{v}_{\mathrm{j}}\right)=$ even. In $\mathrm{V}_{\mathrm{n}}(\mathrm{T})$, there exist subsets $\mathrm{A}_{1} \subset \mathrm{A}$, $\mathrm{A}_{2} \subset \mathrm{A}$ and $\mathrm{B}_{1} \subset \mathrm{B}, \mathrm{B}_{2} \subset \mathrm{B}$ such that if $\operatorname{deg}\left(\mathrm{v}_{\mathrm{i}}\right) \forall \mathrm{v}_{\mathrm{i}} \in \mathrm{A}_{1}$ is odd, then $\operatorname{deg}\left(v_{i}\right) \forall V_{i} \in A_{2}$ is even. Similarly for $B_{1}$ and $\mathrm{B}_{2}$. In $\mathrm{PV}_{\mathrm{n}}(\mathrm{T}), \operatorname{deg}\left(\mathrm{v}_{\mathrm{i}}\right) \forall \mathrm{V}_{\mathrm{i}} \in \mathrm{A}_{1}$, is even and $\operatorname{deg}\left(\mathrm{v}_{\mathrm{i}}\right) \forall \mathrm{v}_{\mathrm{i}} \in$ $A_{2}$ is odd. Similarly it is true for the subsets $B_{1}$ and $B_{2}$. Hence there exists at least one subset containing the vertices of odd degree. Hence $\mathrm{PV}_{\mathrm{n}}(\mathrm{T})$ is noneulerian.

\section{References}

[1] Gudagudi.B.R, Some Topics in Graph Theory. Doctoral Thesis, Karnatak University, Dharwar (1975).

[2] Harary.F, Covering and packing in graphs - I. Annals of New York Academy of Science, 175(1970), 198205.

[3] Harary.F, Graph Theory. Addison - Wesley, Reading, Mass (1969).

[4] Harary.F. and Schwenk. A. J, Evolution of the path number of a graph: Covering and Packing in graph II. Graph Theory and Computing, Ed.Read, R.C. Academic Press, Newyork (19), 39 - 45.

[5] M.H.Muddebihal and Jayashree.B.Shetty, characterization of vict graph of graph, IRJPA-6(2), Feb (2016), 238-246.

[6] Stanton R.G, Cowan.D.D. and James L.O, Some results on path numbers. Proceedings of the Louisiana Conference on Combinatorics, Graph Theory and Computing (1970), 112 - 135

Volume 5 Issue 6, June 2016 www.ijsr.net 